\title{
Risk Management in the Local Government of Indonesia: Drivers, Conditions, and Strategies
}

\author{
Oktaviani Ari Wardhaningrum ${ }^{1 *}$, Kartika $^{1}$
}

\author{
${ }^{1}$ Department of Accounting, Economic and Business Faculty, University of Jember, Jember, Indonesia \\ ${ }^{*}$ Corresponding author. Email: oktaviani.ariw@unej.ac.id
}

\begin{abstract}
Risk management is an emerging issue in the Indonesia government. This study seeks to reveal why and how risk management applied in local government. A case study conducted at the Banyuwangi Regency Government, which was one of the initiators of risk management in Indonesia. In-depth interviews conducted with 19 participants from three work units, namely the Public Works Agency, the Regional Financial and Asset Management Agency, and the Inspectorate. Data analysis uses the constant comparative method with NVivo. The results show that the development of risk management triggered by regulations, preventing corruption, and synchronizing with risk-based audits. There are obstacles such as no specific teams to handle it, the risk of knowledge and awareness not evenly distributed in all work units, and there are no coercion rules for work units. Implementation of risk management in local governments requires the right strategy. Keywords: risk management, local government, risk-based audit, prevent corruption
\end{abstract}

\section{INTRODUCTION}

As economic, social, and political changes rapidly grow, the risk becomes unavoidable. For sustainability and development of operations reason, organizations need to ensure that risks are managed effectively and require a robust internalization of risk culture. Organizations need a guarantee that risks that will occur can be predicted, anticipated, overcome, and managed properly. Risk is essential to be considered and managed the existence and the impact that will be caused.

In the context of government, there are some risks from both external and internal factors that must be considered by government organizations, such as hazard, financial, operations, strategy, and reputation risks [1]. Hazard risks include natural disasters, fires, theft, and criminal acts. Financial risks, such as price changes, liquidity, and loans. Operational risks such as community service, proper planning, and cybersecurity. Strategic risks include demographic, cultural and social change, technological innovation, and political risks such as misconduct policies and procedures, misuse of government resources, and fraud or mismanagement.

This research is important for two reasons. Firstly, fill in the gaps in risk management research in the government environment that is still rarely conducted and published. Characteristics of different government organizations with business organizations will contribute new knowledge on the topic of risk management. Secondly, the practitioners of the government need this kind of research to complement their practices. They need an in-depth study from academics as a basis for reference in making policies, regulations, and technical implementation regarding risk management.
Typical problems that arise in the implementation of programs or activities are the quality of implementation that are not by the targets set and the risk of being exposed to corruption [2]. The causes of those problems are as follows: first, the not fulfilment of work time targets, because of unexpected technical problems in the field. Besides, the capability and quantity of human resources do not match the specifications and needs of the work with the type of program or activity carried out.

Second, the activity cannot be carried out because suddenly, there is a budget cut at unit work even though it has been budgeted. It can occur because the planning and budgeting process has not considered carefully the risks that might occur. Also, the priority scale for determining annual programs and activities has not been carefully synchronized with the unit's long- and medium-term plans.

Third, risk control does not cover all aspects of the organization. The existing risk control system is still limited to applications for the internal audit process. There are several missing things from the internal audit application [3]; examples of budget cuts and HR that are less qualified cannot be detected or controlled from the audit application because this application is only designed for the audit process.

Fourth, a risk management culture has not yet been formed. It is because the leaders have not yet committed to civilizing and socializing risk management in the organization. It is proven that there are no regional regulations regarding risk management, and there are no leaflets or slogans attached at all levels of the organization.

The question in this study is how risk management can control the quality of government activities and their relation to risk-based auditing. This research is limited to the context of the Banyuwangi Regency because it is still rare for local governments in Indonesia to implement risk management. 


\section{RESEARCH METHOD}

\subsection{Methodology}

This research uses a qualitative case study method. In the context of local government, the risks that arise in the implementation of a program or activity will very likely occur. Control of the course of the program or activity needs to be done to maintain the fulfillment of the expected time and quality targets. Meeting this target raises a high level of complexity because the course of a program or activity has many influencing factors such as planning suitability, budget accuracy, running human resources, management support, the technology used, and other external factors. The case study method is suitable for use in the context of problems that are occurring, complex, and essential to be investigated [4], [5].

\subsection{Data Collection and Analysis}

The object in this research is the Banyuwangi Regency Government. The reason for choosing this object is because the Banyuwangi Regency Government has implemented a risk-based audit. Also, the Banyuwangi Regency Government Inspectorate, as an internal control unit, is developing risk management applications for all work units. This study focuses on selecting three work units, namely the Inspectorate, the Financial Management Agency and the Asset Management (BPKAD), and the Public Works Agency (DPU). The Inspectorate was chosen because this work unit became an internal control center that carried out risk-based audits and developed risk management. BPKAD was chosen because this work unit was a supporter of the treasury, administration, and reporting of each program or activity. DPU was chosen because this work unit is a work unit that can represent the complexity of various risks and controls.

This research used in-depth interviews with 19 participants consisting of top, middle-level managers, and technical staff from the three work units above. Besides, this research also uses documentation data such as vision, mission, work unit strategy. This research also explores documents relating to risk management, such as risk-based audit manuals, risk mitigation tables that they have created, as well as laws and regulations that are relevant to this research. The results of the transcript of all in-depth interview records and documentation data were processed using grounded theory techniques [6]. The researcher conducted the stages of open coding, axial coding, and selective coding using NVivo [7].

\section{RESULTS AND DISCUSSION}

\subsection{History and Motivation of Risk Management in the Banyuwangi Regency}

In addition to improving the effective control system, risk management is arranged in the framework of preventing corruption. With this risk management, the risks that might arise can be reduced or eliminated in action or work in each unit. In this risk management, each risk is identified, and alternative risk management is made [8]. So, it is expected that fraud and corruption could be reduced or even eliminated. The development of risk management in the Banyuwangi Regency government is also intended to assist the KPK (Corruption Eradication Commission) task in eradicating corruption in the local government, especially in the Banyuwangi Regency and an effort to make the Banyuwangi Regency free from corruption in 2019.

The Banyuwangi District Government has developed and implemented a risk-based internal audit. With the implementation of risk management in work units, the implementation of risk-based internal audits will be easier to apply and more efficient.

\subsection{Risk and Control}

Local governments carry out programs and activities to ensure development and services to the community. According to the Minister of Home Affairs Regulation No. 13 of 2006 , the program is a translation of the unit policy to achieve the unit mission. While the activities are part of the program carried out by one or more units. Based on the definition in the regulation, it can be concluded that the program is a manifestation of the mission of a unit, while activities are specific activities to support programs that can be implemented in more than one unit.

Within each program and activity, there is a risk that must be managed so that program and activity objectives can be achieved [9]. In this section, the researcher tries to identify the risks that might occur in the programs and activities of the Regional Government of the Banyuwangi Regency. Banyuwangi Regency classifies programs and activities into five functions, that is mandatory affairs-basic services, mandatory affairs-non-basic services, preference affairs, general government, supporting affairs for general government affairs. To simplify this classification, researchers divide programs and activities into three types, namely: service to the community (programs/activities carried out by units that provide services directly to the community, namely DPU), supervision (programs/activities in unit that have responsibilities in the field of supervision, namely Inspectorate), and supporting (programs/activities in this field support the implementation of programs/activities in other units, namely BPKAD). Researchers conducted interviews with 19 participants from three work unit levels that reflected this division, namely DPU in the field of service to the community, Inspectorate in the field of supervision, and BPKAD in the field of support.

The first risk that might occur is a political risk. For example, in the election of village heads, candidates for village heads ask for support from the Cipta Karya and Spatial Planning concerning infrastructure in the village of the prospective village head. It relates to the DPU program, which is a rural infrastructure development program. Concerning political risks, this program may not be evenly distributed throughout the village, but only certain regions that support individual village heads. 
"... village heads who are running again, he needs support from the infrastructure of the Public Works Office" - P15 Political risk is not only limited to the election of village heads. The election of other regional heads, such as regents or governors up to the presidential election, can pose political risks to programs carried out by agencies that deal with services to the community.

The other risk is complaints. Programs for service to the public are the most vulnerable programs exposed to the risk of complaints because they deal with third parties. The risk of a complaint in its development can penetrate the realm of law. For example, public complaints about damaged roads, the subsequent process of presumption of innocence that the road budget is not used according to standards, it can proceed to legal issues. This risk is very closely related to the potential risk of corruption. If there is a risk of complaints that spread to corruption cases, the OPD concentration is divided to serve the community and resolve legal issues (including the risk of wasting time).

"... there was an opinion from the community that the work was bad, or there was a report from the community that to law enforcement officers, then to the inspectorate the work was not appropriate ..." - P18

"... law enforcement officers do not see the report as true or not, as soon as there is a report ... the process is, this thought is indicated, suspected, suspected, so that when we become ... we become this work we should be able to finish it in a certain period, but our concentrate is divided ... "- P15

"... if the potential for corruption is actually in any part, yes, if the potential for corruption is so that anyone can play in their respective fields ..." - P17

The risk of complaints can also occur for projects with an auction system. It is possible that auction partners who do not work on infrastructure according to standards, giving rise to complaints from the public. If that happens, the partner will be reprimanded and asked to work on the project following the Work Order (SPK). If the partner does not acknowledge this, the partner can make a repeat complaint to the appropriate office. Even if the partner has a problem, the DPU must be responsible for the mistakes made by the partners. It is related to inherent risk.

Default risk can be in the form of planning risk. This risk can occur in any field because it is an inherent risk that is inevitable or is likely to occur. Planning risk is defined as a mismatch between planning and implementation, for example, programs/ activities that on time, time, place error, unit of quantity/ price, or proportion - reputational or wrong sequence in implementing the program. Planning risk is very closely related to the risk of error implementation. The higher the risk of planning, the greater the risk of error implementation. The risk of mismanagement that exceeds the tolerance level or threshold can result in a high potential for legal risk (the potential for corruption). The risk of this error can occur both on the internal side and on the external side.

Supervising consultants are expected to conduct supervision under procedures and standards previously stated. However, the supervising consultant, who is also the executor, can make mistakes. Supervisory consultants are not always in the project area and cannot oversee projects 24 hours a day. Also, other mistakes that can occur are violations of agreed procedures. If this happens, the DPU provides sanctions in the form of verbal reprimands, written reprimands, up to termination of contracts, and blacklists to supervisory consultants who commit violations. This sanction applies both to the supervisory consultant and to the partners.

Banyuwangi Regency DPU also conducts online control through e-mondal (e-monitoring and control). Through emondal, supervision, and control to supervisors from the office (non-tender supervisor) and supervisory consultant (tender supervisor) who are on duty in the field can be done online or in real-time.

Excellent communication is a useful tool for controlling risk. Communication between Banyuwangi Regency local government personnel is carried out through a variety of media, ranging from formal media in the form of regular meetings and evaluations every day through morning breakfast, to informal information through groups on social media. The ease of communication has an impact on the ease of getting information so that if there is a potential risk can be done quickly. Coordination and communication are also carried out with village, village, and NGO institutions to reduce the risk of complaints due to community ignorance of government programs.

\subsection{Factors Influencing Risk Management Implementation}

The main factor that triggers the implementation of risk management is the need to identify and manage risk. Risk management is seen as a tool for early identification of corruption. By managing risk properly, it is expected that the prevention of corruption can be carried out. A healthy and corruption-free government environment is a condition that triggers the implementation of risk management.

Another condition that influences are political conditions. The fact that the head of government can change once every 5-10 years is one of the triggers for the importance of risk management implementation. Different heads, different policies are a different reality that often occurs in government. Besides, political factors can also trigger program priorities for "successful teams" or community areas that support the head of government. This risk can arise at the beginning of the democratic party (election) and is likely to always arise at every turn of the leaders.

Another condition that triggers the implementation of risk management is the different characteristics of the programs/activities in each unit. Obligatory affairs, optional affairs, general government, and support have different characteristics. For example, the Public Works Department of Cipta Karya and Spatial Planning classified as compulsory matters that are supportive of other units and have a high budget value considered to have a high risk as well.

Construction work is indeed considered to have a high risk related to the nominal budget attached to the work. On the other hand, the assessment of a risk in a program is not necessarily only seen from the budget of the program, because many factors that can affect the risk.

Overloaded work conditions can also trigger the need for risk management implementation. Job overload can cause significant delays to the work that must be done, which in 
turn can cause burnout to employees. In this case, risk management can be used as a guide to doing work and map work that is important, not important, and urgent, nonurgent, and high, medium, and low-risk jobs.

\subsection{Constraints in Implementing Risk Management}

Data obtained from personnel interviews of Banyuwangi Regency Government employees shows that personnel commitment is a factor that supports the implementation of risk management. Banyuwangi Regency Government has an excellent work culture seen from the values shared by employees and the synergies that are seen between employees [10].

Factors that can hinder the implementation of risk management in the Banyuwangi Regency include external factors, for example, partners who are only concerned with profit. Then also from the sanctions regulations that may be given to external parties considered not to provide a deterrent effect. For example, if a partner has a problem and is blacklisted, the individual partner can still take part in the auction using another legal entity

\subsection{Strategies for Implementing Risk Management}

There are several strategies for implementing risk management. Several strategies have been carried out by the Banyuwangi Regency Government, and there have not been carried out. The strategy that has not yet been carried out is a documented risk management SOP. So far, risk management has been implemented but has not been explicitly stated in a document/ manual. The implementation of risk management is only an informal internalization in each individual. It is better to make documentation of risk mapping so that individual perceptions of risk management can be aligned and can be implemented in all lines of government (goal congruence). Another strategy that can be done is to look at trends between planning and targets in previous years. If in the previous year the target had been exceeded, this year's target could be adjusted to the previous year's target. Whereas if it has not been exceeded, a target can be adjusted, for example, a decrease in the target. Associated with a budget that is not the same every year and the possibility of a budget deficit that occurs must also be considered in setting targets. It relates to the risk of implementation errors that are not following the plan. Establish good coordination and communication with all internal and external parties. Strategies for implementing risk management can also be carried out by holding specialized training to equalize the perceptions of all stakeholders and enhance human resource capabilities.

An important strategy that needs to be done is to use information systems as a tool to force work units to implement risk management. In the budgeting process, work units are required to fill possible risks, degrees of risk, and coping strategies if risks occur in every program and activity that they propose in the budget. If the work unit does not fill in the three things in the budgeting information system, then the budget submission process will not be able to proceed further. The overall discussion is shown in Figure. 1.

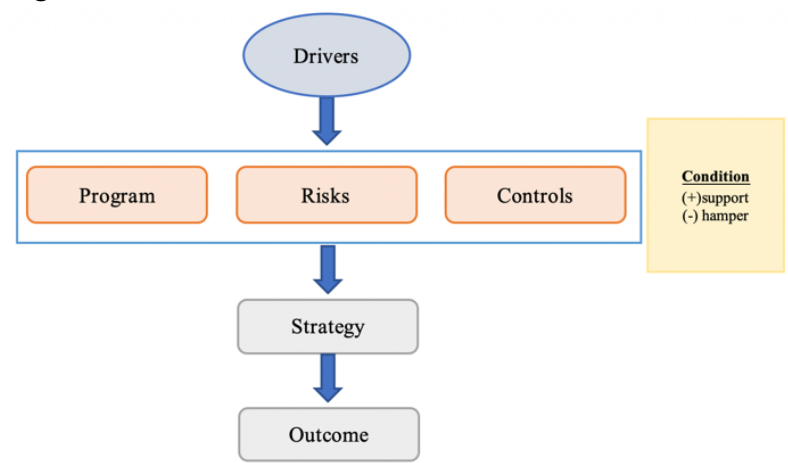

Figure 1 Strategy of Risk Management Implementation

\section{CONCLUSION}

This research succeeded in uncovering the triggers, the conditions of influence, and the strategy of early implementation of risk management in government entities. The main trigger for implementing risk management is a request from the KPK to develop a corruption prevention system. Generally, some risks that arise in the implementation of programs and activities are a political risk, planning risk, and the risk of meeting the target activities. Some obstacles that arise in the implementation of risk management are that there are no coercive rules and comprehensive personnel understanding about risk management. The strategies that can be done are risk management training as a means of equating perceptions comprehensively manner. Also, the formality of the rules applied in the budgeting information system is needed as a means of communication, control, and coercion.

This research has not revealed further how to work units identify, measure, mitigate risks, and impact implementation. It is a limitation of this study because the object of the research turned out to be still at the beginning of the implementation of risk management. Further research should start to explore in each stage of risk management implementation.

\section{ACKNOWLEDGMENT}

Authors wishing to acknowledge LP2M University of Jember and KeRis research grants as the foundation of this research.

\section{REFERENCES}

[1] T. Stanton and D. W. Webster, Managing Risk and Performance: A Guide for Government Decision Makers. John Wiley \& Sons, 2014. 
[6] A. Strauss and J. Corbin, Basics of qualitative research techniques. Sage publications Thousand Oaks, CA, 1998 .

[7] P. Bazeley and K. Jackson, Qualitative data analysis with NVivo. Sage Publications Limited, 2013.

[3] M. B. Romney and P. J. Steinbart, Accounting Information Systems, Global Edition. Pearson Australia Pty Limited, 2017.

[4] R. K. Yin, Case study research and applications: Design and methods. Sage publications, 2017.

[5] S. B. Merriam and E. J. Tisdell, Qualitative research: A guide to design and implementation. John Wiley \& Sons, 2015.
[8] T. Aven, "Risk assessment and risk management: Review of recent advances on their foundation," Eur. J. Oper. Res., vol. 253, no. 1, pp. 1-13, 2016.

[9] E. N. Hatvani, "Risk analysis and risk management in the public sector and in public auditing," Public Finan. Q., vol. 1, no. 7, 2015.

[10] J. Rose, L. S. Flak, and Ø. Sæbø, "Stakeholder theory for the E-government context: Framing a valueoriented normative core," Gov. Inf. Q., vol. 35, no. 3, pp. 362-374, 2018. 